considered sufficient for a long period of time. As a fact, no request has been made in these cases for a repetition of the certificates, the parents not having been again supplied with the form for the purpose. Had this request been made and not complied with there would have been more excnse for the action of the education officials. What is really happening is that a deliberate attempt is being made, on the plea of carrying out the recent Act, to withdraw from the general practitioner, or at least from one, like myself, who is not in the good books of the officials, the right of saying when a child who is a patient of his may or may not attend school and to make "the school doctor" the sole judge in such cases. If this succeeds the natural result must be that parents will see that they will be saved trouble and also the expense of certificates by employing "the school doctor" to attend their children in place of their family medical man; and even if this were not so but the decision of the family doctor were liable to be revised by "the school doctor" the prestige of the former must suffer in consequence.

In my case the two "school doctors" are personal friends and, of course, in no way to blame for what is being done. But it happens that the local education officials have a grudge against me-and I suspect many of the education committee also-for having had the temerity to publicly attack their administration of the Education Acts in the interests of the children in the Hendon schools, and I have little doubt that this is an attempt of some or other of these persons to injure my practice. But whether so intended or not it is clear that if the Act is to be thus used to oust the general practitioner from his care of the children of his poor patients it will ruin the practices of those whose income largely depends upon such cases. What remedy have I for this? It can easily be carried on without the knowledge of either "the school doctors" or myself. And a time might come when "the school doctor" was no longer a personal friend but possibly a none too scrupulous rival. If other general practitioners are finding themselves in the same predicament, I shall be glad to hear from them with a view of taking combined action if it should prove necessary. And I should value, Sir, your opinion on the proper course to take. I am, Sir, yours faithfully,

HenRY BAzETT, M.A., M.R.C.S. Eng., L.R.C.P. Lond. Rossall, Hendon, June 26th, 1908.

* * We append the copy of the letter addressed by the secretary of the Hendon education committee to the parent of one of the children who have been absent upon Mr. Bazett's advice, and we fail to see what right he has to summon the parent and child to a consultation with another medical man.

DEAR SIR,-The Attendance Officer reports that your son Sidney has been away from School for some time owing to illness and that a medical certificate has not recently been provided. This is to inform you that the School Medical Officer will attend the Council Offices at 3.30 P.M. on Friday, when the attendance of your son and yourself is requested. Yours faithfully,

JAMFS ANDERSON.

Secretary to the Committee.

We trust that Mr. Bazett's suggestion that action is being taken by the Hendon education committee upon private rather than public grounds is an error; but whatever the reason may be which has led the committee to seek to get Mr. Bazett's medical opinion over-ridden by the school medical officer the action is a grave error in policy as well as in manners.-ED. L.

\section{OATMEAL DIET IN THE TREATMENT OF DIABETES.}

To the Editor of THE LANCET.

SIR,-In reference to your annotation on the oatmeal diet of diabetes in The LANCET of June 27th it may be interesting to send you a note of a case recently under my care.

A man, aged 67 years, subject to gouty glycosuria intermittently for a number of years, at length gave evidence of pronounced diabetes. At the same time he took with relish to the morning meal of porridge. Then one day quite suddenly he was reported to me by the nurse to have "gone off" the oatmeal and it was dropped out of his dietary. It was also close about this time that his condition became aggravaled-thirst, polyuria, wasting. Within a week the presence of diacetic acid in his urine was found by ferric chlorido test. Treatment with the alkalies potass. bicarb. and sod. citrate only slightly delayed the ensuing restlessness, delirium, and coma. I should add that the sugar was for the most part of the time as much as eight grains to the ounce and gangrene had started in the foot at the commencement of my attendance.

Hackney, July 8th, 1908.

I am, Sir, yours faithfully,

\section{REGOLADO. \\ To the Editor of THE LANCET.}

SIR,-In the précis of the Lombardian lake resorts appearing in THE LANCEr last year, Sept. 14th, no mention was made of Regolado, the omission being an oversight on the writer's part. Reposing on the mountain side vis-à-vis with Menaggio and slightly to the northward, Regolado is 500 feet above Como lake. The hydropathic establishment which mainly constitutes the resort is attained by a rackand-pinion railway. I gather during the summer Italians are catered for, though not long since an effort was made to attract winter visitors. - I am, Sir, yours faithfully,

Aldeburgh, Suffolk, June 29th, 1908.

H. B. SYMoNs.

\section{MANCHESTER. \\ (FROM OUR OWN CORRESPONDENT.)}

\section{Labelling of Poisons.}

ON June 26th a case came before the Salford stipendiary where a firm of what are called "store chemists" was summoned for a breach of Section 13 of the Pharmacy Act by selling a poison, the bottle containing it not being distinctly labelled with the name and address of the firm. It appears that in May last some laudanum and soap liniment was bought for $2 d$. at one of Messrs. J. L. Smith's shops in Cross-lane and the label only showed that Messrs. J. L Smith had branches in Manchester, Salford, and Pendleton instead of having the name and the address of the place where it was purchased. For the defence it was urged that the firm was well known and that "it would be a great hardship to have separate labels printed for the bottles at each branch shop." There are various ideas of what constitutes a hardship, but in selling poisons over the counter it is desirable, even for the seller, that mischance or evil intent should be guarded against as far as possible, though it should entail some slight inconvenience, miscalled a "hardship." One of these safeguards is that the purchase of the poison is more easily traced when the label gives the address of the shop where it was bought than where it leaves you free to wander from one "branch" to another through Manchester or Salford. Printing is not in these days very costly, and the "branch" must be very weak if it cannot afford labels of its own. The stipendiary said no doubt the firm was well known, but the Act stated that the name and address where the article was purchased must be given. "It was not a bad case, and there would be a fine of 10s. and costs." The sale of poisons should be jealously guarded and no foolish remarks about it being a hardship to carry out the law should be brought forward in favour of relaxing the precautions now existing.

\section{Medical Golfers.}

Amid the numerous golf clubs of this part of the world the Manchester and District Medical Golfers' Association holds quite a respectable position. It numbers 200 members and on July 4th 107 competitors met at Worsley for the annual tournament. The day was very hot and the ground was hard, so that the conditions were less than paradisiacal, even to the most enthusiastic devotee of this fascinating and fashionable cult. One of the players found the heat, the hard ground, and the behaviour of the nails in his boots such a trying combination that he took off his boots and played from the third hole in his socks. But the relief thus obtained did not bring him success and his bootless return to the clubhouse was greeted with genial merriment. Dr. H. C. Evison of Salford won the cup and displaced Dr. J. Massey of Pendleton, who, however, took the captain's prize and the Walter gold medal, 